\title{
Degradation of phthalate esters in floor dust at elevated relative humidity
}

\author{
Ashleigh Bope, Sarah R. Haines, Bridget Hegarty, Charles H. \\ Weschler, Jordan Peccia, Karen C. Dannemillar
}

Version Post Print/Accepted Manuscript

Citation Ashleigh Bope, Sarah R. Haines, Bridget Hegarty, Charles J. Weschler, (published version) Jordan Peccia, Karen C. Dannemiller. "Degradation of phthalate esters in floor dust at elevated relative humidity." Environmental Science: Processes and Impacts (2019).

DOI: $10.1039 /$ C9EM00050J

\section{How to cite TSpace items}

Always cite the published version, so the author(s) will receive recognition through services that track citation counts, e.g. Scopus. If you need to cite the page number of the author manuscript from TSpace because you cannot access the published version, then cite the TSpace version in addition to the published version using the permanent URI (handle) found on the record page.

This article was made openly accessible by $U$ of $T$ Faculty. Please tell us how this access benefits you. Your story matters. 


\section{Degradation of phthalate esters in floor dust at elevated relative \\ 2 humidity}

3

4

5

6 $7 \quad$ Peccia $^{4}$, and Karen C. Dannemiller ${ }^{1,2 *}$

*Corresponding author: Karen C. Dannemiller, Department of Civil, Environmental \& Geodetic Engineering, Environmental Health Sciences, Ohio State University, 470 Hitchcock Hall, 2070 Neil Ave, Columbus, OH 43210, Dannemiller.70@osu.edu, 614-292-4031

25

Ashleigh Bope ${ }^{1,2,3 \#}$, Sarah R. Haines ${ }^{1,2,3 \#}$, Bridget Hegarty ${ }^{4}$, Charles J. Weschler ${ }^{5,6}$, Jordan

8

1. Department of Civil, Environmental \& Geodetic Engineering, College of Engineering, Ohio State University, Columbus, OH 43210

2. Division of Environmental Health Sciences, College of Public Health, Ohio State University, Columbus, $\mathrm{OH} 43210$

3. Environmental Science Graduate Program, Ohio State University, Columbus, OH 43210

4. Department of Chemical and Environmental Engineering, Yale University, New Haven, CT 06520

5. Environmental and Occupational Health Sciences Institute, Rutgers University, Piscataway, NJ 07102

6. International Centre for Indoor Environment and Energy, Department of Civil Engineering, Technical University of Denmark, Lyngby, Denmark 


\section{Abstract}

Phthalate esters are present at elevated concentrations in floor dust, and resuspension of

28 dust represents a major source for human exposure to chemicals. Biodegradation of phthalates

29 occurs in aquatic systems and soils but has not been demonstrated in house dust. The goal of this

30 study was to quantify indoor phthalate ester degradation through both biotic and abiotic

31 mechanisms. Worn carpet squares were embedded with dust and incubated for one to six weeks

32 at equilibrium relative humidity (ERH) levels of 50, 80, 85, 90, 95, and 100\%, and nine

33 phthalates were measured. Removal was observed for DEHP, BBzP, DiNP, DiDP, and DMP

$34(\mathrm{p}<0.05)$ when incubated under elevated relative humidity conditions. Abiotic and biotic losses

35 were examined separately using dust spiked with deuterated di(2-ethylhexyl) phthalate (d-

36 DEHP) that was embedded in carpet and incubated at 100\% ERH. Abiotic processes resulted in a

$3710.1 \%( \pm 1.1 \%$, standard error $)$ to $69.6 \%( \pm 4.8 \%)$ decrease in total d-DEHP after one week

$38(\mathrm{p}=0.03)$ and a $27.2 \%( \pm 1.4 \%)$ to $52.0 \%( \pm 2.1 \%)$ decrease after three weeks $(\mathrm{p}=0.008)$.

39 Biodegradation resulted in a decrease in total d-DEHP after one week, ranging from 5.9\%

$40( \pm 8.9 \%)$ to $8.5 \%( \pm 1.7 \%)(\mathrm{p}=0.07)$ and a $1.7 \%( \pm 3.9 \%)$ to $10.3 \%( \pm 4.5 \%)$ decrease after three

41 weeks $(\mathrm{p}=0.044)$. Metatranscriptomic-based analysis indicates that fungi found in carpet dust

42 express genes capable of degrading phthalate esters via various biochemical processes (including

$43 \quad \beta$-oxidation and hydrolysis). Overall, these results support the hypothesis that phthalate losses in

44 floor dust are due to a combination of abiotic and microbial degradation at $\geq 80 \% \mathrm{ERH}$.

46 Environmental Significance

Phthalate esters are only one example of human-made esters that are used as additives in

48 commercial products and are known constituents of house dust. Other examples include 
organophosphate-, adipate-, and sebacate esters. A number of these are of public health concern.

50 In this study, we observed degradation of phthalates in house dust at elevated relative humidity

$51(\mathrm{RH})(\geq 80 \%$, ) with both biotic and abiotic mechanisms contributing to the observed degradation.

52 Similar degradation processes may impact other human-made esters that are found in house dust.

53 This work contributes to improved understanding of microbial activity and the fate of human-

54 made esters in our homes, especially under conditions with available moisture.

\section{Introduction}

57 Phthalate esters (phthalates) are commonly found in the indoor environment. These

58 plasticizers originate from building materials, PVC plastics, and personal care products ${ }^{1}$ and are

59 readily released into the environment since they are not covalently bonded to the polymers.

60 Exposure sources include diet, unintentional house dust ingestion, indoor air inhalation, and

61 dermal absorption ${ }^{2}$. Exposure from non-dietary pathways alone can exceed tolerable daily intake

62 levels for children ${ }^{3}$. A survey conducted by the National Health and Nutrition Examination

63 Survey (NHANES) in the United States found that all participants had phthalate metabolites

64 present in their urine ${ }^{4}$. Phthalates are a significant concern to human health because certain

65 phthalates cause endocrine disruption by mimicking estrogenic compounds ${ }^{5-8}$. Specific concerns

66 include development and reproductive effects ${ }^{1}$ such as altered semen quality ${ }^{9}$ and altered

67 response to allergens ${ }^{10}$.

68 Phthalate degradation can be efficient in systems such as wastewater ${ }^{11,12}$ and soils ${ }^{13}$.

69 Degradation in the environment can occur both biologically ${ }^{12-17}$ and chemically ${ }^{18,19}$, though

70 biological degradation is the predominant route in surface waters, soils, and sediments ${ }^{17}$.

71 Biological degradation reactions include hydrolysis and transesterification ${ }^{14,15}$. One pathway 
72 includes $\beta$-oxidation with either de-esterification/dealkylation or trans-

73 esterification/demethylation ${ }^{20,21}$. Chemical reactions include hydrolysis, oxidation by hydroxyl

74 radicals, and direct photolysis ${ }^{17}$. Hydrolysis typically produces a monoester and alcohol,

75 followed by a second hydrolysis step to form phthalic acid and another alcohol. Under

76 appropriate conditions, phthalic acid can dehydrate to form phthalic anhydride. Our previous

77 work showed that microbial growth and activity in house dust can occur at elevated relative

78 humidity ${ }^{22}$, and that a diversity of microbial functions occur ${ }^{23}$. The availability of moisture in

79 the air above about $80 \%$ relative humidity produces microbial growth and activity in dust ${ }^{22,23}$.

80 However, there have been no investigations of the contributions of chemical and biological

81 processes to degradation in house dust, where phthalates can contribute up to $1 \mathrm{mg} / \mathrm{g}$ to the

82 weight of the dust ${ }^{24}$ but moisture is often limited.

83 The goal of this project was to determine percent loss and degradation rates for common

84 phthalates in the home environment under elevated relative humidity conditions ( $\geq 80 \%$ ) through

85 both abiotic and biotic mechanisms. We hypothesize that elevated relative humidity conditions

$86(\geq 80 \%)$ will lead to phthalate degradation in house dust through both chemical and microbial

87 processes, and we will determine the relative contribution of each. This study demonstrates that

88 elevated relative humidity results in both chemical and microbial degradation of phthalates in

89 house dust embedded in carpet. Further study is needed to determine removal under lower

90 moisture conditions.

91

92 Methods

93 We collected carpet and dust from a home and incubated theses samples at various

94 relative humidity levels while measuring phthalate concentrations before and after. Additionally, 
95 we conducted a spike experiment to separate chemical and microbial degradation contributions.

96 In this experiment, some carpet samples were spiked with a deuterated phthalate (di(2-

97 ethylhexyl-3,4,5,6-d4) phthalate) and compared to sterile controls.

98 Carpet and dust collection. Initial analysis was conducted on the same carpet used in a previous

99 study and with methods described previously ${ }^{22,23}$. Briefly, worn, medium-pile, nylon carpet

100 samples were collected from a single-family home in Massachusetts, USA in September 2014

101 (Site A). This carpet was used exclusively for the analysis described here, except for an

102 additional analysis in the spiked experiment. For this additional analysis, designed to distinguish

103 microbial from abiotic degradation, carpet and dust were collected from three homes in Ohio,

104 USA over the course of 2017-2018 (Sites B, C, and D). Sections were removed, wrapped in

105 aluminum foil, and sealed in polyethylene bags. Dust from the same home was collected from

106 the occupants' vacuum cleaner bags for inoculation in the matched carpet. Dust was sieved to

$107300 \mu \mathrm{m}$, mixed, and stored at room temperature. Dust and carpet were never frozen prior to use

108 to avoid disruption of microbial communities.

109 Carpets sections were cut into $10 \mathrm{~cm} \mathrm{x} 10 \mathrm{~cm}$ squares and embedded with $0.5 \mathrm{~g}$ of dust

110 collected from the same home as the carpet. Dust was not embedded in the $1 \mathrm{~cm}$ section near the

111 edge of the carpet to avoid edge effects. Samples were placed in $3.8 \mathrm{~L}$ glass temperature and

112 relative humidity-controlled chambers covered with parafilm.

113 For the first "natural" experiment, we analyzed samples incubated in the previous study (Site

114 A), including one week at 50, 80, 85, 90, 95, and 100\% equilibrium relative humidity (ERH) to

115 determine how change in relative humidity might influence degradation over one week. We

116 extended the time period to one to six weeks at 85 and 100\% ERH to determine degradation rates

117 at these two ERH levels. The samples at 100\% ERH were excluded after week 3 when extensive 
118 visible mold growth was present on the sample. For this study, we consider values $\geq 80 \%$ ERH to 119 be elevated.

120 For the second "spiked" experiment, we spiked dust samples from Sites A-D (250 mg each) 121 with $10 \mu \mathrm{g}$ di(2-ethylhexyl) phthalate-3,4,5,6-d4 (d-DEHP) in $100 \mu \mathrm{L}$ methanol (AccuStandard,

122 New Haven, CT, USA) and incubated them at 100\% ERH for one and three weeks. These spiked 123 samples were monitored over time. Three different sample types were prepared as follows: 1) a 124 set of carpet squares and dust samples for each site were sterilized by autoclaving for 60 min and 125 drying for 24 hours prior to spiking; 2) a set of unsterilized dust samples were spiked then 126 embedded into carpet just as in the "natural" experiment; 3) a final set of unsterilized dust 127 samples were spiked and embedded in carpet then frozen at $-80{ }^{\circ} \mathrm{C}$ and never incubated. This

128 final set of frozen samples was used as controls to confirm the spiked concentration. All samples 129 were prepared in triplicate, and the $100 \%$ ERH samples set for one week had six replicates as 130 noted previously ${ }^{22}$. After incubation, dust was collected from the 131 carpet using a $19 \mathrm{~mm}$ x $90 \mathrm{~mm}$ cellulose Whatman thimble inserted into a Eureka Mighty Mite 132 vacuum cleaner with an adapter. Dust was stored at $-20{ }^{\circ} \mathrm{C}$ prior to analysis after incubation.

134 RNA analysis to determine microbial function. The purpose of the metatranscriptomic 135 analysis was to determine microbial function in the "natural," non-spiked samples. RNA analysis 136 was conducted on non-spiked samples incubated at 50\%, 85\%, and 100\% ERH, as described 137 previously ${ }^{23}$. Briefly, after incubation, collected dust was extracted in a sterile, laminar flow 138 hood using the PowerMicrobiome ${ }^{\mathrm{TM}}$ RNA Isolation Kit (MoBio, Carlsbad, CA, USA) modified 139 by increasing the amount of $\beta$-mercaptoethanol to $10 \mathrm{x}$ the recommended concentration. RNA 140 was reverse-transcribed into cDNA using a polyA selection protocol to select for eukaryotic 
141 DNA and sequenced on an Illumina HiSeq 4000 at the Yale University Center for Genomic 142 Analysis. The 75 base pair paired-end reads are archived in the European Nucleotide Archive 143 and can be accessed at PRJEB25059. Read filtering and de novo metatranscriptome assembly 144 were carried out using the Trinity pipeline ${ }^{25}$ with details published previously ${ }^{23}$.

145 Sequencing of the fungal metatranscriptome allowed us to look at several potential pathways

146 for phthalate degradation. We compiled a list of genes known to have the ability to degrade 147 phthalates, as well as some ligninolytic enzymes that have been hypothesized to have phthalate 148 degradation potential ${ }^{26,27}$. Among these, di(2-ethylhexyl)phthalate esterase and fungal cutinase 149 are known to be able to degrade di(2-ethylhexyl)phthalate (DEHP) ${ }^{26}$. Potential products may 150 include mono(2-ethylhexyl)phthalate (MEHP) and phthalic acid ${ }^{28-30}$. Long-chain phthalates, 151 including DEHP, have been shown to also degrade via $\beta$-oxidation (removing one ethyl group 152 from a side chain at a time) to DEP and then either de-esterified/dealkylated or trans153 esterified/demethylated to phthalic acid ${ }^{20,21}$. Additionally, we examined whether any annotated 154 sequences had a "phthalate metabolic process" or "phthalate catabolic process" gene ontology 155 (GO) term annotation. As no contigs were found to have either of these GO terms, we also 156 compiled a list of parent GO terms related to the specific enzymes known to degrade phthalates 157 as a proxy for phthalate degradation potential.

159 Phthalate detection. An aliquot of $100 \mathrm{mg}$ of collected dust was weighed into a $40 \mathrm{~mL}$ glass 160 vial that had been baked at $450{ }^{\circ} \mathrm{C}$ for 8 hours with a Teflon cap. A total of $3 \mathrm{~mL}$ of a 3:1 161 hexane:isopropanol solution was added, and the sample was sonicated for 30 minutes. The 162 solution was transferred to a phthalate-free polypropylene tube (cat. no. 339650, Nalgene Nunc 163 International, Rochester, NY, USA) and centrifuged at 10,000 g for 10 minutes. The supernatant 
164 was transferred to a new baked glass vial. For the one-week spiked samples only, the pellet and 3

$165 \mathrm{~mL}$ of methanol was added to the original glass vial and the mixture was sonicated for 30

166 minutes. After centrifugation as described above, the two fractions were injected separately. The

167 methanol extraction was discontinued after the initial round of sample processing because no

168 additional compounds were detected in the methanol fraction on the gas chromatograph/mass

169 spectrometer. Solutions were injected into an Agilent gas chromatograph with Agilent HP5MS,

$17030 \mathrm{mx} 0.250 \mathrm{~mm}$ column connected to an Agilent mass spectrometer using a $1 \mu \mathrm{L}$ splitless

171 injection. The oven program consisted of $120^{\circ} \mathrm{C}$ for $1 \mathrm{~min}$ then $20{ }^{\circ} \mathrm{C} / \mathrm{min}$ to $300{ }^{\circ} \mathrm{C}$ for $5 \mathrm{~min}$.

172 Results were analyzed and quantified with ChemStation software (Agilent). A dilution series of

173 standards was used to create a standard curve. We detected dimethyl phthalate (DMP), diethyl

174 phthalate (DEP), diisobutyl phthalate (DIBP), di(n-butyl) phthalate (DnBP), di(2-

175 ethylhexyl)phthalate (DEHP), butyl benzyl phthalate (BBzP), di-n-octyl phthalate (DnOP),

176 diisononyl phthalate (DINP), and diisodecyl phthalate (DiDP). We used dimethyl isophthalate

177 and dibenzyl phthalate as recovery standards and benzyl benzoate as an injection standard.

178 Benzyl benzoate served as an internal standard for quantitation and was used as a response

179 reference for the standard curve (SI Figure 1) and remained constant in all samples. Dimethyl

180 isophthalate and dibenzyl phthalate served as recovery standards. A sample blank without dust

181 was processed using the same protocol as the spiked samples. Instrument blanks were run in

182 triplicate before each set of samples and standards.

183 Samples were also injected on an Agilent LC MS with a C18 column using the following 184 program: ramp from 5\% to $95 \%$ solvent B (acetonitrile and $0.1 \%$ formic acid) in solvent A 185 (water and $0.1 \%$ formic acid) over 15 minutes with a flow rate of $0.5 \mathrm{~mL} / \mathrm{min}$. Standard curves 
186 from a dilution series were generated to measure mono(2-ethylhexyl)phthalate (MEHP) and 187 phthalic acid in a subset of samples.

188 After initial sample processing, subsequent samples of carpet and dust from three additional 189 different homes were tested for phthalate degradation in the spiked experiment. These samples 190 were processed in the same manner as the initial analysis with the following exceptions.

191 Solutions were injected into a Thermoquest Trace GC 2000 gas chromatograph with Agilent 192 DB5MS, $30 \mathrm{mx} 0.250 \mathrm{~mm}$ column connected to a Finnigan PolarisQ mass spectrometer. The 193 oven program consisted of $80^{\circ} \mathrm{C}$ for $1 \mathrm{~min}$ then $20^{\circ} \mathrm{C} / \mathrm{min}$ to $300^{\circ} \mathrm{C}$ for $3 \mathrm{~min}$. The injection 194 was a $1 \mu \mathrm{L}$ splitless injection. Results were analyzed and quantified with Xcalibur data system 195 (ThermoFisher). No additional LC MS analysis was performed.

197 Statistics. Statistical analyses were performed using Stata Statistical Software, release 15

198 (StataCorp LLC., College Station, TX, USA) to evaluate phthalate degradation indicated by a 199 decrease in concentrations within our experiments. Simple linear regression was used to evaluate 200 the degradation of each phthalate detected in the natural experiment over time at $100 \%$ and $85 \%$ 201 ERH. Data from the nine phthalates incubated at 100\% ERH were tested first for a statistically 202 significant decrease in phthalate concentration over the three weeks tested. Only the phthalates 203 with $\mathrm{p}<0.05$ were evaluated for degradation at $85 \%$ ERH over the six weeks tested. We also 204 tested BBzP and DEHP for degradation at 85\% ERH due to their steep slope values at $100 \%$ 205 ERH and because it is possible that the degradation is not linear. Degradation of the spike D206 DEHP was measured as the percent loss of the phthalate from the total concentration delivered 207 over a three-week period, but it was determined that it did not follow a linear trend, so linear 208 regression was not used. Instead, we performed a two-sample t-test to compare the mean percent 
209 loss between week zero and both week one and week three of the incubation. Phthalate

210 degradation for the spike experiment was assessed using the mean percent loss of all four sites.

\section{Results}

213 All targeted phthalates were detected in the dust from Site A. DEHP had the highest initial

214 concentration at $0.029 \mu \mathrm{g} / \mathrm{mg}$ dust, while other concentrations ranged from $0.0021-0.0057$

$215 \mu \mathrm{g} / \mathrm{mg}$ dust (DIBP - BBzP) (Figures 1 and 2). Over the time range and ERH levels measured,

216 there was no evidence for degradation of DEP, DIBP, DnBP, or DnOP. There was indication of

217 biotic/abiotic degradation for higher molecular weight phthalates DINP, and DiDP $(\mathrm{p}<0.05)$ and,

218 to a lesser extent, $\mathrm{BBzP}(\mathrm{p}=0.055)$ and lower molecular weight phthalate $\mathrm{DMP}(\mathrm{P}<0.05)$.

219 Although the decrease in DEHP in the natural experiment was not statistically significant, there

220 was a mean $13.5 \%$ decrease in DEHP concentrations per week. All phthalates except DEP

221 showed a negative rate of change suggesting there is an overall downward trend in phthalate

222 concentration over time (Table 1). Degradation rates are also listed in Table 1 and range from -

2230.11 to $-1.1 \mu \mathrm{g} / \mathrm{g}$-dust/week for statistically significant compounds. The degradation rate for

224 DEHP was $-3.9 \mu \mathrm{g} / \mathrm{g}$-dust/week but was not statistically significant, possibly because the data

225 was not linear. Thus, this was tested using a t-test for the spike experiment.

226 We also tested for losses at $85 \%$ ERH for phthalates that showed a statistically significant

227 reduction at 100\% $\mathrm{ERH}$, in addition to $\mathrm{BBzP}$ and DEHP which had two of the top three largest

228 degradation rates. BBzP and DINP $(\mathrm{p}<0.05)$ concentrations were significantly reduced under

229 these conditions. All phthalates except DMP exhibited a negative rate of change demonstrating

230 an overall downward trend in phthalate concentrations over time (Table 1). 
This analysis, shown in Figures 1 and 2, was not designed to determine the relative

232 contributions of biotic and abiotic degradation mechanisms. Rather, the measurements quantified 233 total losses of the phthalate in the house dust via any process.

235 Microbial and abiotic degradation. To determine the relative contribution of biotic and abiotic

236 losses, we spiked d-DEHP into both sterilized and non-sterilized dust and incubated it in carpet

237 for one and three weeks. The total concentration of d-DEHP decreased in incubated samples

238 undergoing both microbial growth and in sterile controls (Figure 3A). In this figure, the line

239 labeled "chemical" indicates degradation from sterilized samples. The line labeled "microbial"

240 indicates the difference in degradation between non-sterile and sterile samples (i.e., $\underline{\text { degradation }}$

241 due to microbial growth only, not including the chemical component).

242 Chemical degradation rates were always higher than microbial degradation rates. For the

243 incubated sample from Site A, after one week about 8.5\% d-DEHP was lost to microbial

244 degradation and an additional $10 \%$ was lost to chemical degradation. After three weeks, there

245 was no additional microbial driven loss, but chemical driven loss continued, totaling about $27 \%$.

246 We repeated this experiment with carpet and dust from three additional homes (Figure 3B-D).

247 After one week, chemical driven loss was 22.5\%, 32.6\% and 69.6\% for samples from Sites B-D,

248 while microbial driven loss was substantially smaller (5.9\%, 7.3\% and 0\% for Sites B-D,

249 respectively). At three weeks, chemical driven loss continued for samples from Sites B and C,

250 but appeared to reverse for the sample from Site D. This apparent reversal may be a sampling

251 artifact. No further microbial driven loss was observed for Site B and Site C samples, while

252 microbial driven loss increased to $10 \%$ for the Site D sample. A two-sample t-test of the mean

253 percent losses for all four sites combined indicated there was a statistically significant difference 
254 in the percent loss at the start of the experiment and at week one of the incubation for abiotic

$255(\mathrm{p}=0.03)$ but not microbial $(\mathrm{p}=0.07)$ degradation. At week three, both abiotic $(\mathrm{p}=0.008)$ and

256 microbial $(\mathrm{p}=0.044)$ percent losses for all the sites were statistically significant. Although DEHP

257 did not show degradation in our natural experiment based on linear regression, we demonstrated

258 that d-DEHP is degraded in our spike experiment.

259 The first step in the degradation of DEHP is typically the production of its monoester,

260 mono(2-ethylhexyl)phthalate (MEHP). Measurement of MEHP in Site A from both sets of

261 experiments (non-spiked and spiked) provide additional insights regarding the loss of DEHP

262 from settled dust. In the sterile control after one week, MEHP's concentration increased slightly

263 compared with its initial concentration; the increase in MEHP's concentration was even larger in

264 the non-sterile "growth" sample. d-MEHP was observed in the initial sample, and after one week

265 its concentration in the sterile sample was no different, while its concentration in the "growth"

266 sample was slightly higher (Figure 4A). Phthalic acid, a degradation product of MEHP, was also

267 measured in these samples and was above the detection limit in only the sample that experienced

268 growth. d-Phthalic acid had a substantially higher concentration in the "growth" sample than in

269 either the sterile control or the initial sample (Figure 4B). d-MEHP and d-phthalic acid in the

270 "initial” samples are hypothesized to come from the d-DEHP solution used for spiking. MEHP

271 was measured in samples incubated at different ERH levels for one week, and an increase

272 relative to its initial concentration was seen only at 100\% ERH (Figure 4C). MEHP was also

273 measured in samples at 100\% ERH for up to three weeks and 85\% ERH for up to six weeks. At

$274100 \% \mathrm{ERH}$, the concentration increased initially, and then appeared to decrease from weeks two

275 to three (perhaps due to degradation of MEHP to phthalic acid). At $85 \%$ ERH, the concentration 
276 gradually increased over the six weeks, but at the end of six weeks MEHP's concentration was

277 still less than half the level measured after only two weeks at 100\% ERH (Figure 4D).

278

279 Metatranscriptomics and microbial function. To determine whether the metatranscriptomic

280 data provides evidence of phthalate degradation we identified 16 enzymes with phthalate

281 degradation potential and 15 Gene Ontology (GO) terms associated with phthalate degradation.

282 No direct evidence of phthalate degradation potential was found using the GO terms; however,

283 indirect evidence points to the metabolic processes necessary for phthalate degradation,

284 including contigs annotated with GO:0046274, or lignin catabolic process (Table 2). Similarly,

285 the enzymatic evidence points to the potential of these cells for phthalate degradation (Table 3).

286 Phthalate degradation enzymes fall into three main classes: hydrolases (EC:3.-.-.-),

287 oxidoreductases (EC:1.--..-), and lyases (EC:4.-.-.-). Of those enzymes with a known ability to

288 degrade phthalates, only E10 3,4-protocatechuate deoxygenase and fungal cutinase were found

289 in the metatranscriptome. This evidence is suggestive but cannot confirm whether DEHP is

290 degraded in this manner in our samples.

291 The metatranscriptomics data suggests some differential expression of genes with phthalate

292 degradation potential at the three relative humidity levels tested (SI Figure 2). Although most

293 contigs with a cutinase annotation had no statistically significant changes in gene expression

$294\left(\mathrm{p}_{\mathrm{adj}}<0.05\right)$, for one out of the three contigs, gene expression increased at $85 \%$ compared to $50 \%$

295 ERH. None of the contigs with an E10 3,4-protocatechuate deoxygenase annotation were found

296 to be differentially expressed between any of the conditions. For those contigs with a laccase

297 annotation, 7 out 26 contigs were up-regulated at 100\% compared to 50\% ERH, 10 out of 26 
298 contigs were up-regulated at $100 \%$ compared to $85 \% \mathrm{ERH}$, and none were differentially

299 expressed between $85 \%$ and $50 \%$ ERH.

300 Previous studies have shown that phthalates with side chains longer than DEP can be

301 shortened via $\beta$-oxidation and then converted to phthalic acid via either trans-esterification or de-

302 esterification ${ }^{20,21}$. Although evidence of this pathway can be seen in the GO terms and enzymes

303 (Tables 1 and 2), we cannot say definitively whether they are acting on phthalate esters. While

304 most contigs with a $\beta$-oxidation annotation are not differentially expressed, nearly twice as many

305 contigs are up-regulated at $100 \%$ versus $50 \%$ ERH and nearly four times as many contigs are up-

306 regulated at 100\% versus 85\% ERH (SI Figure 3). We also see evidence of possible microbial

307 degradation via hydrolysis (Table 3), and we cannot definitively say which pathway(s) is/are

308 used.

309

310 Discussion

311 Microbial activity in the indoor environment may alter chemicals, and we need to understand

312 the conditions under which this may occur. Degradation of phthalate esters could be either

313 beneficial (due to phthalate removal) or harmful (because exposure to the degradation products

314 may also have negative health effects ${ }^{31-33}$ ). We provided preliminary evidence that

315 biodegradation of phthalate esters in the indoor environment occurs and may contribute to

316 removal of these potentially harmful compounds under elevated relative humidity.

317 Degradation in sampled dust/carpet. In this proof-of-concept study, we employed extreme

318 relative humidity conditions. Future studies are required to determine whether microbial

319 degradation occurs under more typical building conditions; and, if it does, to what extent. Our

320 data at $85 \%$ ERH does point to the potential for this to also occur over longer periods of time 
321 (such as many weeks, several months, or possibly years) at a more realistic humidity level. In the 322 present investigation, DMP, BBzP, DINP all showed a decrease in concentration over time. In 323 other systems, such degradation has been stimulated with the addition of appropriate

324 microorganisms ${ }^{11}$. However, we did not attempt to separate biotic and abiotic processes for any 325 of these compounds except for DEHP.

326 At this time, we are unable to provide an explanation for why microbial degradation of DEHP 327 appears to cease after one week in samples from a home in Massachusetts (Figure 3A) and two 328 homes in Ohio (Figures 3B and 3C). This is a complex and dynamic system with many 329 microbes and chemicals present and changing in concentration. One potential hypothesis is that 330 another degradation product, such as MEHP, 2-ethyl hexanol or the product of another pathway, 331 has built up to inhibit the microbe(s) responsible for degradation. MEHP is known to inhibit 332 cellular processes in other organisms ${ }^{34,35}$, and an increase in MEHP concentration was observed 333 at week two in the Massachusetts home (Figure 4D). 2-Ethyl hexanol is reported to inhibit 334 phthalate degradation under methanogenic conditions ${ }^{36}$. It is also possible that a more preferred 335 energy source became available in the samples from Sites A - C. However, further investigation 336 of this observation is beyond the scope of the present study and will need to be examined in 337 future work.

338 At $100 \%$ ERH, the increasing concentration of MEHP at week one and week two 339 measurements was followed by a decreasing concentration at week three (Figure 4D).

340 Presumably, the initial increase is due to the degradation of DEHP. However, MEHP is also 341 susceptible to hydrolysis and other degradation reactions, producing phthalic acid as one of its 342 products (Figure 4B). Thus, MEHP is both produced and consumed as a consequence of 343 degradation processes. Taken together, Figures 4A and 4B suggest that these reactions are driven 
344 at least partially by microbes, since in both instances the amount of product measured after one

345 week at $100 \%$ ERH is substantially larger for the "growth" condition compared to the sterile

346 condition.

347 Degradation pathways and trends. Our data provides suggestive evidence of the microbial

348 pathways that may be responsible for phthalate degradation in house dust. Degradation of

349 phthalates via $\beta$-oxidation is consistent with our data from the first "natural" experiment, which

350 demonstrated preferential degradation of phthalates with longer side chains (Figures 1 and 2).

351 However, we cannot conclusively link the degradation pathway with the degradation measured

352 in this study based on our data. The presence of fungal cutinase and other ligninolytic enzymes

353 in our metatranscriptome offer another potential avenue of phthalate degradation. Taken

354 together, these results show that microbes growing on dust at various relative humidity levels are

355 expressing genes with phthalate degradation potential, but do not definitively point to a specific

356 enzyme or pathway as being responsible for the microbial degradation of phthalates that we saw

357 in our experiments.

358 Previous studies have generally found that low molecular weight phthalates are more prone to

359 abiotic and biotic degradation than high molecular weight phthalates ${ }^{17,20,28,37-39}$. While the

360 opposite trend was seen here, none of these prior studies were conducted using house dust

361 embedded in carpet and there are other potential reasons that could be investigated further to

362 explain this difference in our samples. Water, soil, and other outdoor systems may not be

363 representative of what occurs in a home. Factors besides molecular weight can also affect

364 degradation. These include temperature, $\mathrm{pH}$, metal content, dissolved oxygen, certain organics,

365 available nutrients, and microbial composition ${ }^{37,38,40}$. In general, phthalates must be dissolved

366 to be bioavailable, and sorption of phthalates to humic material can influence dissolution ${ }^{17}$. 
367 Bioavailability of esters is also dependent on hydrophobicity, charge, size, and even steric effects

368 associated with certain side chains ${ }^{40}$. The trend observed in our study was seen in one home

369 (Site A), which has a certain microbial community and contains dust with a certain chemical

370 composition. Acclimation of the organisms at Site A to certain compounds might further

371 influence degradation rates ${ }^{20,40}$, and high concentrations of DEHP (as occurs in our system) can

372 reduce degradation rates for lower molecular weight phthalates, including DnBP, DEP, and DMP

$373{ }^{20}$. In summary, multiple factors influence phthalate degradation rates. Trends in such rates might

374 vary with the nature of a home, a possibility that should be explored in future work.

375 Relative humidity level may alter microbial degradation of phthalates. Our previous work

376 demonstrated that fungi in house dust at 100\% ERH increased gene expression compared to

377 either $50 \%$ or $85 \% \mathrm{ERH}^{23}$. In particular, fungal cells at 50\% ERH mainly expressed genes

378 related to primary metabolism, while genes for more secondary metabolic processes were

379 expressed as ERH increased ${ }^{23}$. Genes with phthalate degradation potential are associated with

380 both primary and secondary metabolism. For instance, lignin catabolism is a secondary

381 metabolic process ${ }^{41}$ with enzymes capable of phthalate degradation. In this study, some

382 ligninolytic genes demonstrate this pattern of increasing expression with increasing ERH: fungal

383 cutinase expression is up-regulated at $85 \%$ compared to 50\% ERH and laccase degradation is up-

384 regulated at $100 \%$ compared to both $50 \%$ and $85 \%$ ERH. Fatty acid $\beta$-oxidation is a primary

385 metabolic process ${ }^{41}$ with phthalate degradation potential; overall, those contigs with a $\beta$ -

386 oxidation annotation are up-regulated at $100 \%$ compared to both $50 \%$ and $85 \%$ ERH. This

387 mirrors the overall increase in gene expression with humidity seen in our previous work and may

388 be because cells need to conserve resources due to the lack of moisture at $50 \% \mathrm{ERH}^{23}$. As $\beta$ - 
oxidation is a primary metabolic process, it is possible that even at lower relative humidity levels

390 phthalates could be slowly degraded in this way.

391 Exposure implications. As noted at the beginning of this section, the health consequences of

392 these degradation processes may be mixed. Removal of DEHP itself is beneficial for reducing

393 exposure to this compound. However, degradation products such as 2-ethyl hexanol, MEHP,

394 phthalic acid and phthalic anhydride are potentially more irritating or harmful than the parent

395 compound ${ }^{31}$. For instance, 2 -ethyl hexanol has an offensive odor, while phthalic anhydride is

396 known to cause allergic rhinitis and asthma ${ }^{42-45}$. Future work is needed to investigate the extent

397 to which these processes occur under more realistic, long-term building conditions and measure

398 the quasi steady-state levels of intermediate products such as MEHP. Our study was short term

399 (up to six weeks) but at elevated relative humidity levels, and it is unknown how changing either

400 of these parameters will affect concentrations. Dust in the indoor environment typically has a

401 residence time of months to years depending on its location within the structure.

402 Extended periods with extremely high relative humidity should be avoided in homes.

403 Although phthalate esters in dust may degrade faster under such conditions, the production of

404 harmful degradation products coupled with mold growth are anticipated to contribute to adverse 405 health effects ${ }^{46,47}$.

406 Limitations. 1) This proof-of-concept study was conducted with dust and carpet that came 407 primarily from one Massachusetts home, with some exploration of d-DEHP degradation in 408 samples from three additional Ohio homes (Figure 3B-D). 2) The portion of the study that 409 explored biotic and abiotic degradation of deuterated DEHP from Sites A-D occurred under 410 extreme conditions of $100 \%$ relative humidity over one to three weeks and needs to be validated 411 under more typical building conditions and more realistic timeframes. With a dataset limited to 
412 only two measurements post spike, linear interpolations are required between weeks one and

413 three. 3) This study was not designed to determine the specific microbial organism(s) responsible

414 for this degradation; this should also be evaluated in future work. 4) The gene expression

415 analysis was only able to generate suggestive (rather than definitive) information on potential

416 phthalate degradation pathways that will also need to be explored in future studies. Future

417 degradation experiments could use radiolabeled compounds to determine if the radioactive label

418 becomes incorporated into the biomass. If we had sequenced to a greater depth, we might have

419 found evidence of more genes that were expressed at very low levels, including more phthalate

420 degradation genes. We were also limited in the metatranscriptomics analysis by a lack of

421 definitive work on which enzymes are responsible for degrading phthalates.

422

423 Conclusions

424 This work demonstrates that phthalate degradation in house dust is possible through both

425 biotic and abiotic mechanisms. At elevated relative humidity, both processes contribute to the

426 overall degradation rate. The removal of higher molecular weight phthalates from indoor dust

427 can be viewed as a positive outcome, but degradation results in the production of alcohols,

428 monoesters, and phthalic acid, which can be dehydrated to form phthalic anhydride. Some of

429 these products may be of greater health concern than their precursors. This study was conducted

430 at elevated relative humidity levels to demonstrate proof-of-concept, and the work needs to be

431 repeated at lower relative humidity levels and for more extended periods of time.

433 Conflicts of Interest

434 The authors declare no conflicts of interest. 
437 Funding was provided by a Microbiology of the Built Environmental Postdoctoral Fellowship

438 from the Alfred P. Sloan Foundation. Bridget Hegarty was funded by the Graduate Research

439 Fellowship Program from the National Science Foundation. The authors would also like to thank

440 Terence Wu and the Yale University West Campus Analytical Core for assistance in sample

441 analysis. Additionally, the authors appreciate insight on sample analysis from Thomas Kwan and

442 Marcia Nishioka.

\section{References}

1. U. Heudorf, V. Mersch-Sundermann and J. Angerer, Phthalates: Toxicology and exposure, International Journal of Hygiene and Environmental Health, 2007, 210, 623634.

2. K. Clark, I. Cousins and D. Mackay, in Phthalate Esters, ed. C. A. Staples, SpringerVerlag, Berlin, Heidelberg, 1 edn., 2003, vol. 3Q, ch. 8, pp. 227-262.

3. G. Bekö, C. J. Weschler, S. Langer, M. Callesen, J. Toftum and G. Clausen, Children's phthalate intakes and resultant cumulative exposures estimated from urine compared with estimates from dust ingestion, inhalation and dermal absorption in their homes and daycare centers, PLoS ONE, 2013, 8, e62442.

4. M. J. Silva, D. B. Barr, J. A. Reidy, N. A. Malek, C. C. Hodge, S. P. Caudill, J. W. Brock, L. L. Needham and A. M. Calafat, Urinary levels of seven phthalate metabolites in the U.S. population from the National Health and Nutrition Examination Survey (NHANES) 1999-2000, Environ Health Perspect, 2004, 112, 331-338.

5. C. A. Harris, P. Henttu, M. G. Parker and J. P. Sumpter, The estrogenic activity of phthalate esters in vitro, Environ Health Perspect, 1997, 105, 802-811.

6. S. Jobling, T. Reynolds, R. White, M. G. Parker and J. P. Sumpter, A variety of environmentally persistent chemicals, including some phthalate plasticizers, are weakly estrogenic, Environ Health Perspect, 1995, 103, 582-587.

7. A. P. van Wezel, P. van Vlaardingen, R. Posthumus, G. H. Crommentuijn and D. T. H. M. Sijm, Environmental Risk Limits for Two Phthalates, with Special Emphasis on Endocrine Disruptive Properties, Ecotoxicology and Environmental Safety, 2000, 46, 305-321. 
8. E. Diamanti-Kandarakis, J.-P. Bourguignon, L. C. Giudice, R. Hauser, G. S. Prins, A. M. Soto, R. T. Zoeller and A. C. Gore, Endocrine-disrupting chemicals: an Endocrine Society scientific statement, Endocrine Reviews, 2009, 30, 293-342.

9. R. Hauser, J. D. Meeker, S. Duty, M. J. Silva and A. M. Calafat, Altered semen quality in relation to urinary concentrations of phthalate monoester and oxidative metabolites, Epidemiology, 2006, 17, 682-691

10. I. Kimber and R. J. Dearman, An assessment of the ability of phthalates to influence immune and allergic responses, Toxicology, 2010, 271, 73-82.

11. P. Roslev, K. Vorkamp, J. Aarup, K. Frederiksen and P. H. Nielsen, Degradation of phthalate esters in an activated sludge wastewater treatment plant, Water Research, 2007, 41, 969-976.

12. R. Kurane, Microbial degradation of phthalate esters, Microbiol Sci, 1986, 3, 92-95.

13. C. D. Cartwright, I. P. Thompson and R. G. Burns, Degradation and impact of phthalate plasticizers on soil microbial communities, Environmental Toxicology and Chemistry, 2000, 19, 1253-1261.

14. S. Chatterjee and P. Karlovsky, Removal of the endocrine disrupter butyl benzyl phthalate from the environment, Appl Microbiol Biotechnol, 2010, 87, 61-73.

15. Y. Okamoto, C. Toda, K. Ueda, K. Hashizume and N. Kojima, Transesterification in the Microbial Degradation of Phthalate Esters, Journal of Health Science, 2011, 57, 293-299.

16. S. Nalli, D. G. Cooper and J. A. Nicell, Metabolites from the biodegradation of di-ester plasticizers by Rhodococcus rhodochrous, Sci Total Environ, 2006, 366, 286-294.

17. C. A. Staples, D. R. Peterson, T. F. Parkerton and W. J. Adams, The environmental fate of phthalate esters: A literature review, Chemosphere, 1997, 35, 667-749.

18. A. Sjoberg and O. Ramnas, An experimental parametric study of VOC from flooring systems exposed to alkaline solutions, Indoor Air, 2007, 17, 450-457.

19. S. Chino, S. Kato, J. Seo and Y. Ataka, Study on emission of decomposed chemicals of esters contained in PVC flooring and adhesive, Building and Environment, 2009, 44, 1337-1342.

20. D. W. Liang, T. Zhang, H. H. Fang and J. He, Phthalates biodegradation in the environment, Appl Microbiol Biotechnol, 2008, 80, 183-198.

21. S. Amir, M. Hafidi, G. Merlina, H. Hamdi, A. Jouraiphy, M. El Gharous and J. C. Revel, Fate of phthalic acid esters during composting of both lagooning and activated sludges, Process Biochemistry, 2005, 40, 2183-2190.

22. K. C. Dannemiller, C. J. Weschler and J. Peccia, Fungal and bacterial growth in floor dust at elevated relative humidity levels, Indoor Air, 2016.

23. B. Hegarty, K. Dannemiller and J. Peccia, Gene expression of indoor fungal communities under damp building conditions: implications for human health, Indoor Air, 2018.

24. S. Langer, C. J. Weschler, A. Fischer, G. Bekö, J. Toftum and G. Clausen, Phthalate and PAH concentrations in dust collected from Danish homes and daycare centers, Atmospheric Environment, 2010, 44, 2294-2301.

25. M. G. Grabherr, B. J. Haas, M. Yassour, J. Z. Levin, D. A. Thompson, I. Amit, X. Adiconis, L. Fan, R. Raychowdhury, Q. Zeng, Z. Chen, E. Mauceli, N. Hacohen, A. Gnirke, N. Rhind, F. di Palma, B. W. Birren, C. Nusbaum, K. Lindblad-Toh, N. Friedman and A. Regev, Trinity: reconstructing a full-length transcriptome without a genome from RNA-Seq data, Nature biotechnology, 2011, 29, 644-652. 
26. Y. H. Kim, J. Lee and S. H. Moon, Degradation of an endocrine disrupting chemical, DEHP [di-(2-ethylhexyl)-phthalate], by Fusarium oxysporum f. sp. pisi cutinase, Appl Microbiol Biotechnol, 2003, 63, 75-80.

27. Y. H. Kim, J. Min, K. D. Bae, M. B. Gu and J. Lee, Biodegradation of dipropyl phthalate and toxicity of its degradation products: a comparison of Fusarium oxysporum $\mathrm{f}$. sp. pisi cutinase and Candida cylindracea esterase, Arch Microbiol, 2005, 184, 25-31.

28. W. Jianlong, C. Lujun, S. Hanchang and Q. Yi, Microbial degradation of phthalic acid esters under anaerobic digestion of sludge, Chemosphere, 2000, 41, 1245-1248.

29. P. Keyser, B. G. Pujar, R. W. Eaton and D. W. Ribbons, Biodegradation of the phthalates and their esters by bacteria, Environmental health perspectives, 1976, 18, 159.

30. G. Engelhardt, P. Wallnöfer and O. Hutzlnger, The microbial metabolism of di-n-butyl phthalate and related dialkyl phthalates, Bulletin of environmental contamination and toxicology, 1975, 13, 342-347.

31. P. Erkekoglu, W. Rachidi, O. G. Yuzugullu, B. Giray, A. Favier, M. Ozturk and F. Hincal, Evaluation of cytotoxicity and oxidative DNA damaging effects of di(2ethylhexyl)-phthalate (DEHP) and mono(2-ethylhexyl)-phthalate (MEHP) on MA-10 Leydig cells and protection by selenium, Toxicol Appl Pharmacol, 2010, 248, 52-62.

32. T. N. Lovekamp and B. J. Davis, Mono-(2-ethylhexyl) Phthalate Suppresses Aromatase Transcript Levels and Estradiol Production in Cultured Rat Granulosa Cells, Toxicology and Applied Pharmacology, 2001, 172, 217-224.

33. J. Reinsberg, P. Wegener-Toper, K. van der Ven, H. van der Ven and D. Klingmueller, Effect of mono-(2-ethylhexyl) phthalate on steroid production of human granulosa cells, Toxicology and Applied Pharmacology, 2009, 239, 116-123.

34. J. Ling, Z. P. Lopez-Dee, C. Cottell, L. Wolfe and D. Nye, Regulation of mRNA Translation Is a Novel Mechanism for Phthalate Toxicity, PLOS ONE, 2016, 11, e0167914.

35. F. Chauvigne, A. Menuet, L. Lesne, M. C. Chagnon, C. Chevrier, J. F. Regnier, J. Angerer and B. Jegou, Time- and dose-related effects of di-(2-ethylhexyl) phthalate and its main metabolites on the function of the rat fetal testis in vitro, Environ Health Perspect, 2009, 117, 515-521.

36. J. Ejlertsson, M. Alnervik, S. Jonsson and B. H. Svensson, Influence of Water Solubility, Side-Chain Degradability, and Side-Chain Structure on the Degradation of Phthalic Acid Esters under Methanogenic Conditions, Environmental Science \& Technology, 1997, 31, 2761-2764.

37. D.-W. Gao and Z.-D. Wen, Phthalate esters in the environment: A critical review of their occurrence, biodegradation, and removal during wastewater treatment processes, Science of The Total Environment, 2016, 541, 986-1001.

38. N. L. Wolfe, W. C. Steen and L. A. Burns, Phthalate ester hydrolysis: Linear free energy relationships, Chemosphere, 1980, 9, 403-408.

39. B. V. Chang, C. M. Yang, C. H. Cheng and S. Y. Yuan, Biodegradation of phthalate esters by two bacteria strains, Chemosphere, 2004, 55, 533-538.

40. T. M. Nolte, K. Pinto-Gil, A. J. Hendriks, A. M. J. Ragas and M. Pastor, Quantitative structure-activity relationships for primary aerobic biodegradation of organic chemicals in pristine surface waters: starting points for predicting biodegradation under acclimatization, Environ Sci Process Impacts, 2018, 20, 157-170. 
558 41. D. Binns, E. Dimmer, R. Huntley, D. Barrell, C. O'Donovan and R. Apweiler, QuickGO:

559 a web-based tool for Gene Ontology searching, Bioinformatics, 2009, 25, 3045-3046.

560 42. R. A. Kern, Asthma and allergic rhinitis due to sensitization to phthalic anhydride: Report of a case, Journal of Allergy and Clinical Immunology, 1939, 10, 164-165.

43. C. A. Maccia, I. L. Bernstein, E. A. Emmett and S. M. Brooks, In vitro demonstration of specific IgE in phthalic anhydride hypersensitivity, American Review of Respiratory Disease, 1976, 113, 701-704.

44. M. Wernfors, J. Nielsen, A. Schütz and S. Skerfving, Phthalic anhydride-induced occupational asthma, International Archives of Allergy and Immunology, 1986, 79, 7782.

45. K. Tarvainen, R. Jolanki, T. Estlander, O. Tupasela, P. Pfäffli and L. Kanerva, Immunologic contact urticaria due to airborne methylhexahydrophthalic and methyltetrahydrophthalic anhydrides, Contact Dermatitis, 1995, 32, 204-209.

46. M. J. Mendell, A. G. Mirer, K. Cheung, M. Tong and J. Douwes, Respiratory and allergic health effects of dampness, mold, and dampness-related agents: a review of the epidemiologic evidence, Environ Health Perspect, 2011, 119, 748-756.

47. W. J. Fisk, Q. Lei-Gomez and M. J. Mendell, Meta-analyses of the associations of respiratory health effects with dampness and mold in homes, Indoor Air, 2007, 17, 284296. 
Figure Legends

581 Figure 1. Measured values found in the site A dust for DMP, DEP, DIBP, and DnBP at different

582 ERH levels for one week, at $85 \% \mathrm{ERH}$ for up to six weeks, or at $100 \% \mathrm{ERH}$ for up to three

583 weeks. Samples were analyzed in triplicate. Points represent mean values and error bars

584 represent standard error. Excepting DMP, there were indications of degradation for lower

585 molecular weight phthalates under $100 \%$ ERH conditions $(\mathrm{p}<0.05)$.

587 Figure 2. Measured values found in the site A dust for BBzP, DEHP, DnOP, DINP, and DiDP at 588 different ERH levels for one week, at $85 \% \mathrm{ERH}$ for up to six weeks, or at $100 \% \mathrm{ERH}$ for up to 589 three weeks. Note the larger ordinate range for DEHP. Samples were analyzed in triplicate, 590 except the point $100 \%$ ERH for one week which was analyzed with six replicates. Points

591 represent mean values and error bars represent standard error. Under 100\% ERH conditions, 592 there were indications of degradation for higher molecular weight phthalates DINP and DiDP $593(\mathrm{p}<0.05)$ and, to a lesser extent, BBzP $(\mathrm{p}=0.055)$. Under 85\% ERH conditions, BBzP and DINP 594 concentrations were significantly reduced $(\mathrm{p}<0.05)$.

596 Figure 3. Biotic and abiotic degradation of deuterated DEHP spiked into carpet from Sites A-D 597 and measured at one and three weeks. The dashed blue line labeled "chemical" indicates 598 degradation from sterilized samples. The solid orange line labeled "microbial" indicates the 599 difference in degradation between non-sterile and sterile samples (i.e., degradation due to 600 microbial growth only, not including the chemical component). The lines indicating microbial 601 and chemical degradation between the measured points at week one and week three are linear 
602 interpolations of the data. Samples were analyzed in triplicate. Points represent mean values and

603 error bars represent standard error. Abiotic processes resulted in a significant decrease in total d-

604 DEHP after one week $(\mathrm{p}=0.03)$ and after three weeks $(\mathrm{p}=0.008)$. Biodegradation resulted in a

605 decrease in total d-DEHP after one week $(\mathrm{p}=0.07)$ and after three weeks $(\mathrm{p}=0.044)$.

607 Figure 4. Phthalate degradation products. A. MEHP and D-MEHP in dust of spike experiment

608 after one week. "Initial" is the amount spiked in for D-MEHP or the initial amount measured of

609 MEHP naturally in the dust. "Sterile" represents the autoclaved dust that was spiked with D-

610 DEHP, and "Growth" represents the non-sterilized dust spiked with D-DEHP. All samples

611 (including initial) were spiked with D-DEHP, which may have contained some D-MEHP. B.

612 Phthalic acid under the same conditions as in A. * represents values that were not detectable. C.

613 Values of MEHP found in the "OD" (original dust) and after incubation at the listed ERH level

614 for one week. D. MEHP in the dust at either 85\% ERH or 100\% ERH for zero to three weeks.

615 Samples were analyzed in triplicate, with the exception of points in C and D at 100\% ERH for

616 one week, which were analyzed with six replicates. Points represent mean values and error bars

617 represent standard error. 

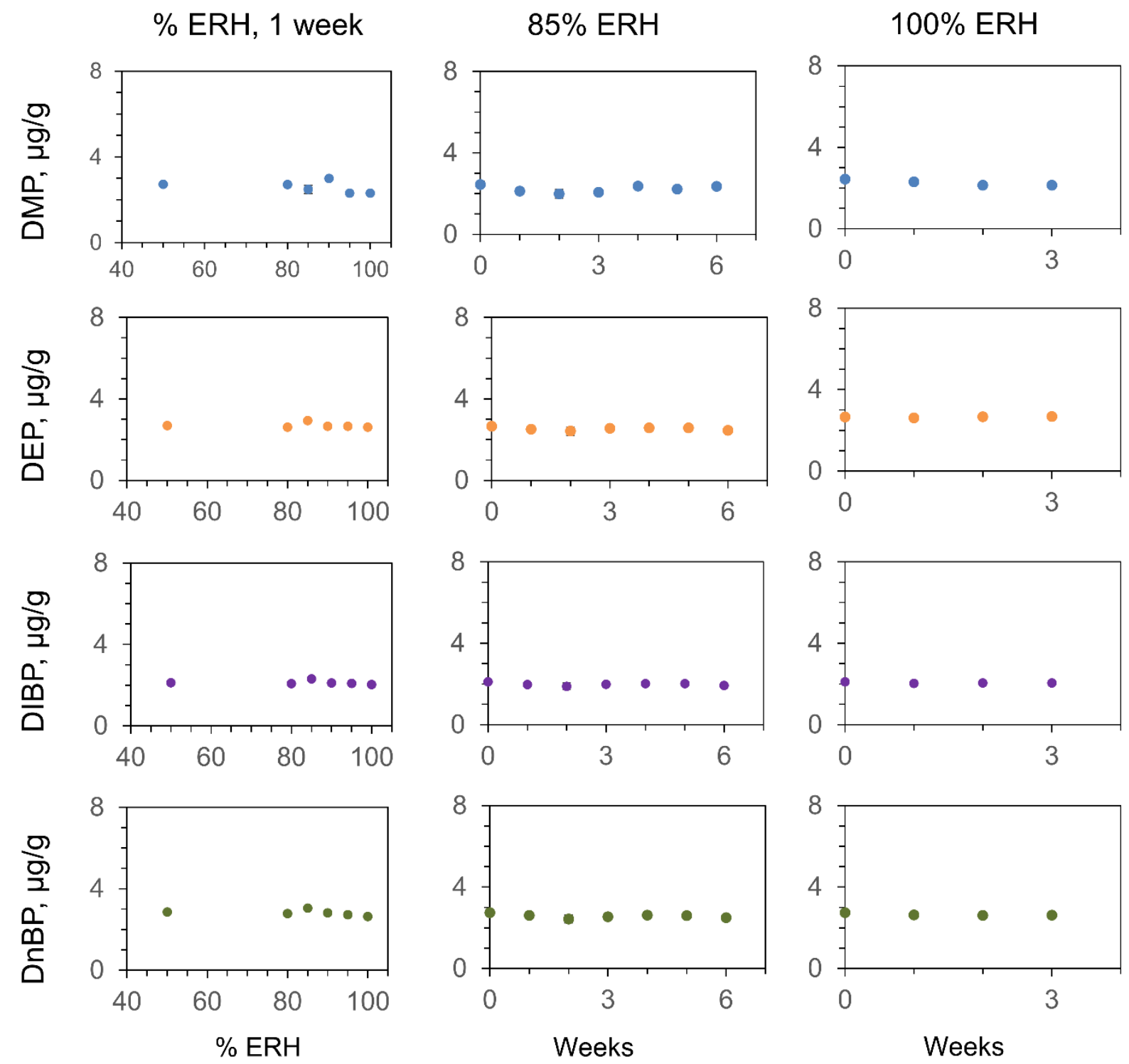

619 Figure 1 

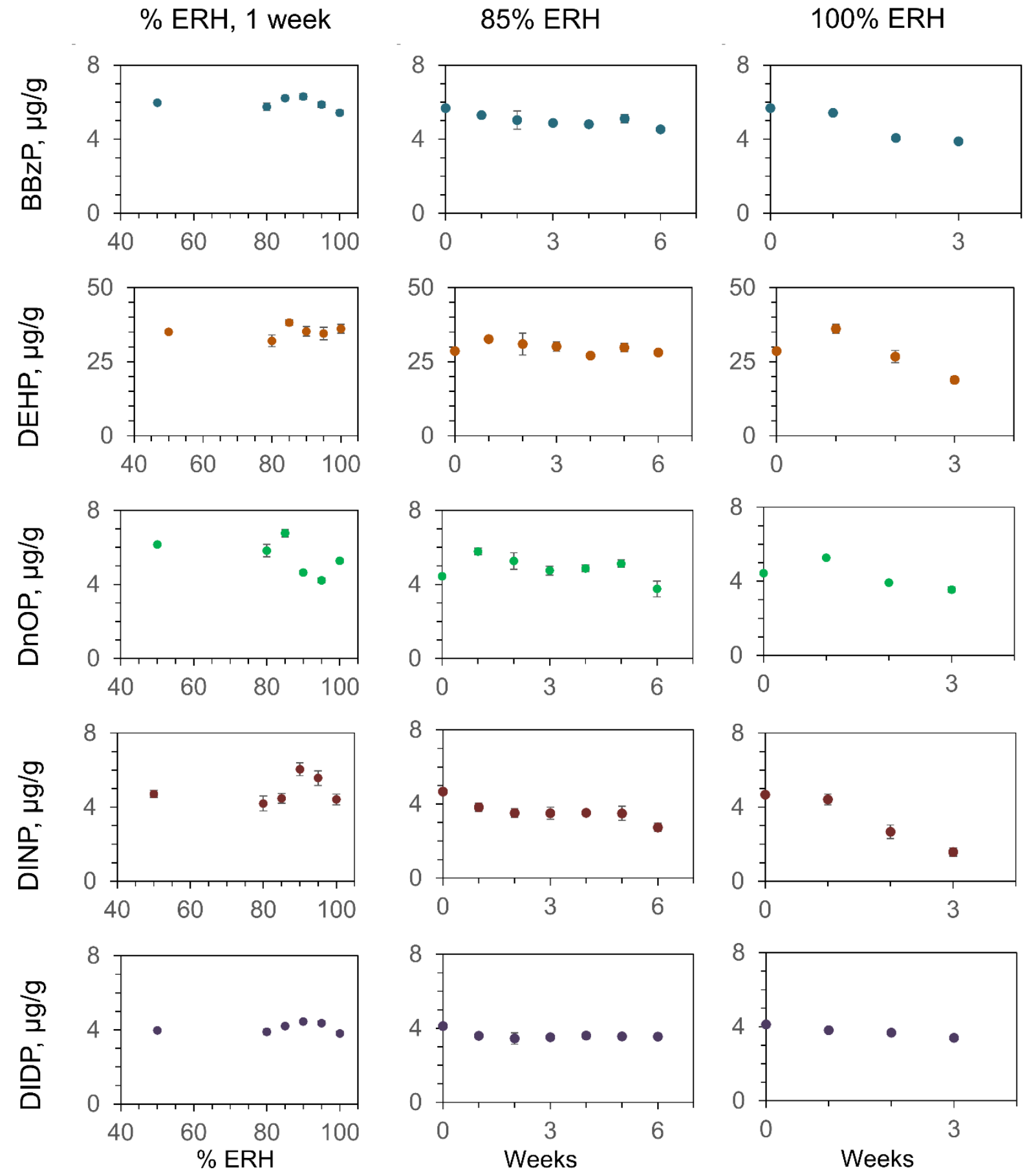

620

621 Figure 2 

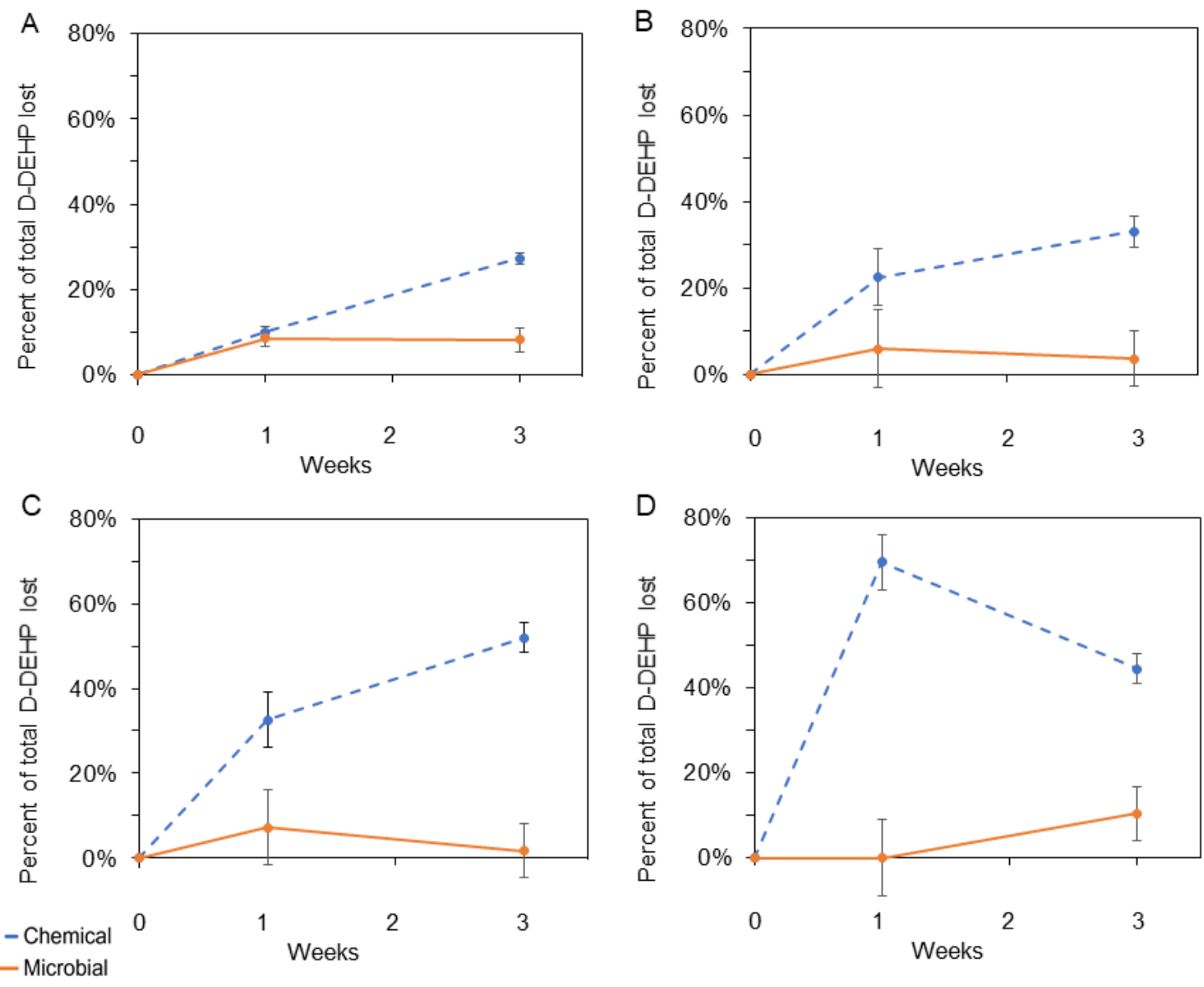

623

624

625

Figure 3 

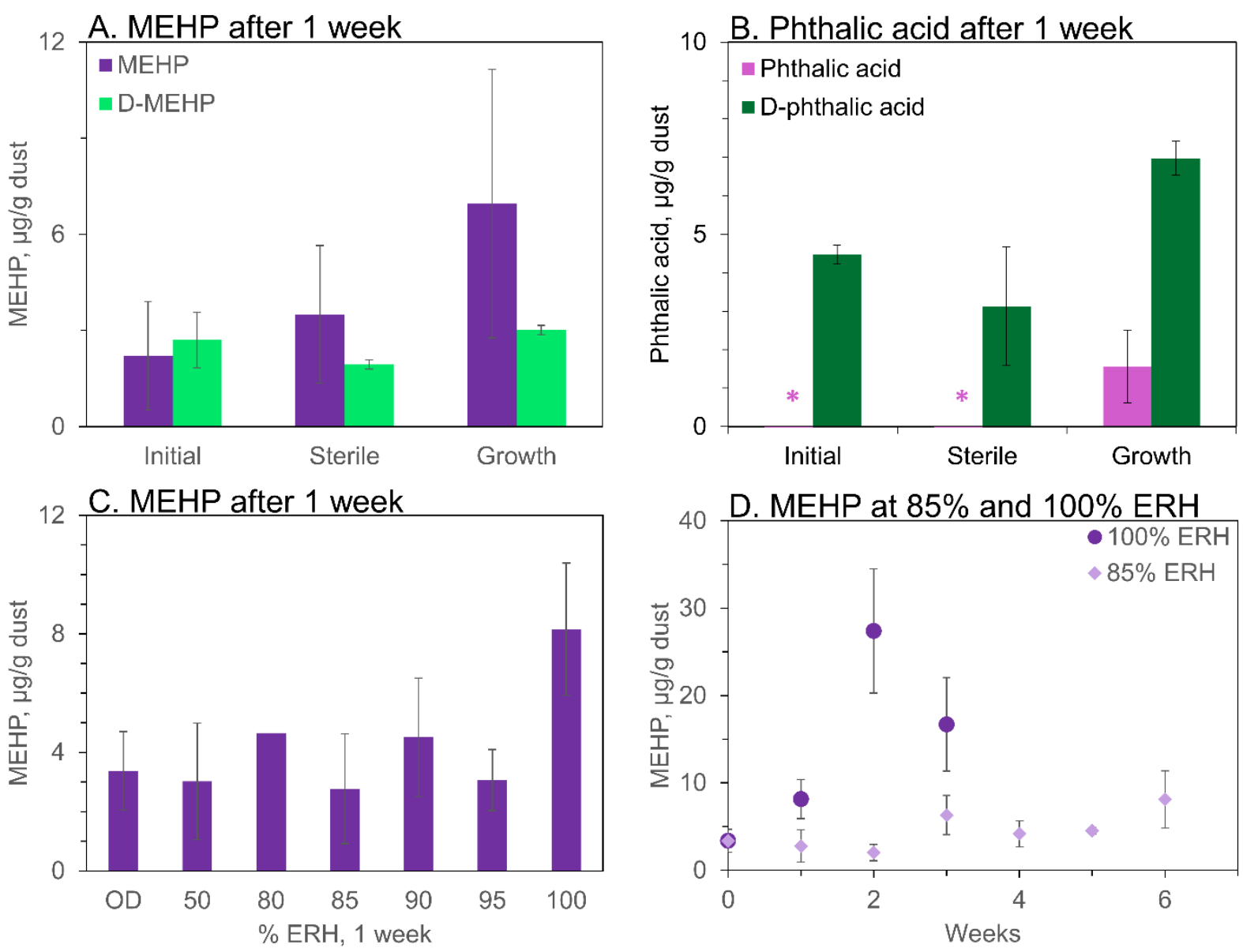

Figure 4 


\section{Table 1}

629 Degradation rates for all phthalates at 100\% ERH and select phthalates at 85\% ERH. Only

630 phthalates that showed potential for degradation at $100 \%$ ERH were evaluated at $85 \%$ ERH.The 631 p-values $<0.05$ are in bold. BBzP and DEHP were also evaluated at $85 \%$ ERH due to their high 632 slope values.

\begin{tabular}{|cccccc|}
\hline Phthalate & ERH & p-value & $\begin{array}{c}\text { Slope } \\
(\boldsymbol{\mu g} / \mathbf{g} \text { dust/week })\end{array}$ & $\begin{array}{c}\text { \% Slope } \\
(\% \text { decrease/week })\end{array}$ & Figure \\
\hline DMP & $100 \%$ & $\mathbf{0 . 0 4 8}$ & -0.11 & $-4.4 \%$ & 1 \\
DEP & $100 \%$ & 0.46 & 0.011 & $0.43 \%$ & 1 \\
DIBP & $100 \%$ & 0.39 & -0.014 & $-0.68 \%$ & 1 \\
DnBP & $100 \%$ & 0.19 & -0.039 & $-1.4 \%$ & 1 \\
BBzP & $100 \%$ & 0.055 & -0.67 & $-12 \%$ & 2 \\
DEHP & $100 \%$ & 0.30 & -3.9 & $-14 \%$ & 2 \\
\hline DnOP & $100 \%$ & 0.31 & -0.40 & $-9.0 \%$ & 2 \\
DINP & $100 \%$ & $\mathbf{0 . 0 3}$ & -1.1 & $-24 \%$ & 2 \\
DiDP & $100 \%$ & $\mathbf{0 . 0 1}$ & -0.23 & $-5.6 \%$ & 2 \\
\hline & & & & & \\
\hline DMP & $85 \%$ & 0.77 & 0.011 & $0.45 \%$ & 1 \\
BBzP & $85 \%$ & $\mathbf{0 . 0 2}$ & -0.15 & $-2.6 \%$ & 2 \\
DEHP & $85 \%$ & 0.30 & -0.40 & $-1.4 \%$ & 2 \\
\hline DINP & $85 \%$ & $\mathbf{0 . 0 1}$ & -0.23 & $-5.0 \%$ & 2 \\
\hline DiDP & $85 \%$ & 0.19 & -0.058 & $-1.4 \%$ & 2 \\
\hline
\end{tabular}




\section{Table 2}

635 Gene ontology (GO) terms with phthalate degradation associations.

\begin{tabular}{|c|c|c|}
\hline Gene Ontology (GO) Term & GO Number & $\begin{array}{l}\text { Found in } \\
\text { metatranscriptome? }\end{array}$ \\
\hline phthalate catabolic process & GO:0046239 & No \\
\hline phthalate metabolic process & GO:0018963 & No \\
\hline $\begin{array}{l}\text { carboxylic acid metabolic process (parent of phthalate } \\
\text { metabolic process) }\end{array}$ & GO:0019752 & Yes \\
\hline $\begin{array}{l}\text { benzyene-containing compound metabolic process } \\
\text { (parent of phthalate metabolic process) }\end{array}$ & GO:0042537 & Yes \\
\hline peroxidase activity & GO:0004601 & Yes \\
\hline fatty acid $\beta$-oxidation & GO:0006635 & Yes \\
\hline lipase activity & GO:0016298 & Yes \\
\hline $\begin{array}{l}\text { oxidoreductase activity, acting on the } \mathrm{CH}-\mathrm{CH} \text { group of } \\
\text { donors, NAD or NADP as acceptor }\end{array}$ & GO:0016628 & Yes \\
\hline $\begin{array}{l}\text { oxidoreductase activity, acting on paired donors, with } \\
\text { incorporation or reduction of molecular oxygen, } \\
\text { NAD(P)H as one donor, and incorporation of two atoms } \\
\text { of oxygen into one donor }\end{array}$ & GO:0016708 & Yes \\
\hline $\begin{array}{c}\text { oxidoreductase activity, acting on diphenols and related } \\
\text { substances as donors, oxygen as acceptor (synonym: } \\
\text { laccase activity) }\end{array}$ & GO:0016682 & Yes \\
\hline hydroquinone:oxygen oxidoreductase activity & GO:0052716 & Yes \\
\hline carboxylyase activity & GO:0016831 & Yes \\
\hline lignin catabolic process & GO:0046274 & Yes \\
\hline dioxygenase activity & GO:0051213 & Yes \\
\hline carboxylic ester hydrolase activity & GO:0052689 & Yes \\
\hline
\end{tabular}


638 Enzymes with known and potential phthalate degradation capabilities. Enzymes in bold were

639 found in our metatranscriptome.

\begin{tabular}{|c|c|c|c|c|}
\hline Enzyme & $\begin{array}{c}\text { EC } \\
\text { number }\end{array}$ & Pathway & $\begin{array}{c}\text { Phthalate } \\
\text { degradation? }\end{array}$ & $\begin{array}{l}\text { Found in } \\
\text { metatranscriptome? }\end{array}$ \\
\hline E1 DAP esterase & 3.1.1.- & $\begin{array}{c}\text { phthalate } \\
\text { biodegradation }\end{array}$ & known & No \\
\hline E2 MAP esterase & 3.1.1.- & $\begin{array}{c}\text { phthalate } \\
\text { biodegradation }\end{array}$ & known & No \\
\hline $\begin{array}{l}\text { bis(2-ethylhexyl) } \\
\text { phthalate esterase }\end{array}$ & 3.1 .1 .60 & $\begin{array}{c}\text { phthalate } \\
\text { biodegradation }\end{array}$ & known & No \\
\hline $\begin{array}{l}\text { E3 PA 4.5- } \\
\text { dioxygenase }\end{array}$ & 1.14.12.7 & $\begin{array}{c}\text { PA and TA } \\
\text { biodegradation }\end{array}$ & known & No \\
\hline $\begin{array}{c}\text { E4 PA 3,4- } \\
\text { dioxygenase }\end{array}$ & 1.14.12.- & $\begin{array}{c}\text { PA and TA } \\
\text { biodegradation }\end{array}$ & known & No \\
\hline $\begin{array}{l}\text { E5 cis-4,5-dihydroxy- } \\
\text { 4,5-dihydrophthalate } \\
\text { dehydrogenase }\end{array}$ & 1.3.1.- & $\begin{array}{c}\text { PA and TA } \\
\text { biodegradation }\end{array}$ & known & No \\
\hline $\begin{array}{l}\text { E6 cis-3,4-dihydroxy- } \\
\text { 3,4-dihydrophthalate } \\
\text { dehydrogenase }\end{array}$ & 1.3.1.- & $\begin{array}{c}\text { PA and TA } \\
\text { biodegradation }\end{array}$ & known & No \\
\hline $\begin{array}{c}\text { E7 4,5- } \\
\text { dihydroxyphthalate } \\
\text { decarboxylase }\end{array}$ & 4.1.1.55 & $\begin{array}{c}\text { PA and TA } \\
\text { biodegradation }\end{array}$ & known & No \\
\hline $\begin{array}{c}\text { E8 3,4- } \\
\text { dihydroxyphthalate } \\
\text { decarboxylase }\end{array}$ & 4.1.1.69 & $\begin{array}{c}\text { PA and TA } \\
\text { biodegradation }\end{array}$ & known & No \\
\hline $\begin{array}{c}\text { E9 4,5- } \\
\text { protocatechuate } \\
\text { dioxygenase }\end{array}$ & 1.13.11.8 & $\begin{array}{c}\text { PA and TA } \\
\text { biodegradation }\end{array}$ & known & No \\
\hline $\begin{array}{c}\text { E10 3,4- } \\
\text { protocatechuate } \\
\text { deoxygenase }\end{array}$ & 1.13.11.3 & $\begin{array}{c}\text { PA and TA } \\
\text { biodegradation }\end{array}$ & known & Yes \\
\hline fungal cutinase & 3.1.1.74 & $\begin{array}{l}\text { ligninolytic } \\
\text { enzymes }\end{array}$ & known & Yes \\
\hline yeast esterase & 3.1.1.- & $\begin{array}{l}\text { ligninolytic } \\
\text { enzymes }\end{array}$ & known & Yes \\
\hline lignin peroxidase & 1.11.1.14 & $\begin{array}{l}\text { ligninolytic } \\
\text { enzymes }\end{array}$ & possible & No \\
\hline $\begin{array}{l}\text { magnanese-dependent } \\
\text { peroxidase }\end{array}$ & 1.11.1.13 & $\begin{array}{l}\text { ligninolytic } \\
\text { enzymes }\end{array}$ & possible & No \\
\hline laccase & 1.10.3.2 & $\begin{array}{l}\text { ligninolytic } \\
\text { enzymes }\end{array}$ & possible & Yes \\
\hline
\end{tabular}

